\title{
Analysis of Stormwater Management Systems: Sustainable Approaches for Wuhan, China
}

\author{
Rong Sheng ${ }^{1} \&$ Nawari O. Nawari ${ }^{2}$ \\ ${ }^{1}$ School of Architecture and Urban Planning, Huazhong University of Science and Teconology, Wuhan, China \\ ${ }^{2}$ School of Architecture, University of Florida, Gainesville, FL 32611, United States \\ Correspondence: Rong Sheng, School of Architecture and Urban Planning, Huazhong University of Science and \\ Teconology, Wuhan, China. Tel: 352-226-9389. E-mail: rongsheng.elina@gmail.com
}

\author{
Received: September 15, 2015 Accepted: November 18, 2015 Online Published: January 26, 2016 \\ doi:10.5539/jsd.v9n1p89 \\ URL: http://dx.doi.org/10.5539/jsd.v9n1p89
}

\begin{abstract}
With the rapid pace of urbanization and drastic transformation of economic form, Wuhan, a central city of China is facing serious inland inundation problems in recent decades. This study intends to alleviate Wuhan's storm water management problems in a sustainable way and give suggestions as to the improvement of residential area storm water management and lakeside wetland protection. Based on the data provided by Geographical Information System, analysis is done to the land form of the whole city and the change of its lake areas, which evidently demonstrates the influences of economic development on the natural environment of the city and reveals the causes of the inundation problems. Taking the population growth, land use and climate change into consideration, this research argues that strategies such as green roof fostering, neighbor-hood water reuse and wetland conservation can make a difference in stormwater drainage and prevention of inland inundation in Wuhan.
\end{abstract}

Keywords: inundation, green roof, watershed reservation, stormwater management, green infrastructure

\section{Introduction}

Stormwater management (SWM) is not a sole domain of construction and engineering; it is an interdisciplinary field combining many subjects such as soil science, ecology and hydrologists. Citizens, land users and planners are linked together by this art and science-mimicking problem. This issue attracts more and more researchers' attention because it's now not only the problem of building drainage to get water out as quickly as possible so that it will not cause flooding. Actually, the control measures have evolved from centralized structure to distribute and onsite practice and from man-made structural methods to natural and biological ones, involving what is called low impact development (LID) measures (Elliott \& Trowsdale, 2007), Water Sensitive Urban Design or WSUD, Sustainable Urban Drainage Systems or SUDS (Elliott \& Trowsdale, 2007) and Innovative Stormwater Management (Marsalek \& Schreier, 2009). In the new ways of storm water management, source control is used more than the original separate storm water pipes or combined sewage (David Butler\&John W. Davies, 2000), which is supported by sustainable approach of environmental design. Sustainable design emphasizes on-site development ordinance and impacts of storm water on environment. Through the development of sustainable design and focused research on stormwater management, various approaches have been discovered and practiced in America.

China is now facing serious problem of city inland inundation. It is a hard problem to solve because it does concern many different departments of Government whose cooperation is crucial in the solution of this issue. Some researchers have already started their works in solving this problem in big cities such as Beijing and Guangzhou. Because of the high speed of China's urbanization city hardened surface grows fast. At the same time, climate change leads to high frequency of extreme weather conditions. Moreover, the city drainage system itself has many problems which directly lead to inundation. According to the investigation done by Ministry of Housing and Urban-Rural Construction of the People's Republic of China in 2010, from 2008 to 2010, 351 cities took part in statistic analysis of inland inundation and $62 \%$ of them are faced with the inland flooding, a problem which not only causes economic drawbacks but also threatens city safety (Zhu Sicheng \& Ren Xiyan 2011). Situation in China is quite complicated, for the land inundation problem is related to many different management departments and different branches of these departments. In tackling this challenge, China still lacks long-term plan, relevant statistics and scientific foundations. Some researches focused only on how to evacuate the inland 
ponded water as quickly as possible, but researches on evacuation and drainage system have certain limitations as they are usually based on small sites and areas.

Wuhan is the political, economic and cultural center of Hubei Province. It is well known for plentiful water. Abundant water comes from the hundreds of lakes and two main rivers Yangzi River and Han River, which join together here in Wuhan. The 110-kilometer shoreline of lakes gives citizens great opportunities and wonderful scenery. About a quarter of the city area is lakeside area. In ancient time Wuhan was an important port for water transportation. The 3500 years of history also gives Wuhan rich culture but this city is now troubled by serious inundation. In June of 2011, Wuhan was attacked by continuous raining days which lasted over a month and 88 spots in the city were flooded (Wuhan Water Resource Management Bureau WWRMB). The inland inundation led to transportation system tie-up. What's more, the polluted water led to the cutting of electricity and shut-down of the clean water supply in some areas of the city. Tens thousands people were influenced by the storm. Similar situation appeared in July of 2013, when heavy rainfall lasted 40 hours and people were besieged in the train station as traffic was halted by queued cars. The direct economic loss of this disaster is up to 2 billion Yuan (Zhou guoqiang. 2013). The flat form of land called Jianghan Plain gives Wuhan opportunities to expand its city area in all the possible directions but at the same time, inland inundation starts to appear. Wuhan local government is also confused because they have already spent money trying to solve this problem but, it still can't be solved well.

Ground water flooding brings problem of pollution in different ways, especially during the raining seasons. The pollutants enter hydrological cycles by way of path, highway surface, road gullies and other sources. Possibility of rainwater pollution is high and the results are severe, which poses challenges for the drainage system of the city. Urban drainage systems have to deal with two kinds of waters: waste water and storm water. In urban drainage history wastewater was connected to ditches and natural streams whose original function being carrying storm water (David Butler \& John W. Davies. 2000). From the late 80s last century Americans started to tackle the problem of storm water pollution. The United States Environment Protection Agency (EPA) joined hands with US government to do investigation and survey through the whole country and to seek the best ways to cope with storm water management problems and city inundation problems.

In the US, storm water management in urban areas is becoming increasingly oriented to the use of low impact development, sustainable urban drainage systems, water sensitive urban design, best management practices (BMP), or low impact urban design and development (LIUDD) for countering the effects of urban growth, wherein the storm water is controlled at its source through detention, retention, infiltration, storage, and retardation (Elliott and Trousdale 2007).These methods include structural measures such as wetlands, ponds, swales, soak ways, infiltration trenches, roof storage systems, detention/retention basins, infiltration basins, bio-retention devices, vegetated filter strips and pervious pavements. Though the storm water management ways vary from place to place and change with climate and geographic features, however, under appropriate conditions, those structural measures prove to be effective (Bhagu R. Chahar1, Didier Graillot \& Shishir Gaur 2012)

By analyzing land forms and climate patterns of Wuhan, this study aims to investigate the main causes of inland flooding and ground water pollution facing Wuhan city and integrate the geographical features of Wuhan with the new approach of sustainable design, to develop suitable strategies for Wuhan to address the inland inundation problem and gives suggestions as to the improvement of residential area storm water management and lakeside wetland protection.

\section{Method}

\subsection{General Model Design}

This study analyzes the geological conditions and special changes to watershed in Wuhan China. Arc GIS is used to provide geographical information to classify the land elevation and watershed shape changing; A data set is used to create raster to see the changes that appear in the area, especially the change of water body shape during the examined period of time. In order to determine the accuracy of the image classification, we specify certain points as sample points to achieve overall accuracy for statistics and add base map for detailed analysis. Land use table is created to describe the land cover type within the studied area. The soil conservation spot is planned for the best suggested storm-water management area in storm Water Park and storm-water recycle. This study will also identify the proper area for water cycle systems and rain gardens. Green roof areas for drainage and water reuse neighbor-hood are specified. On the basis of extensive review of literature and documents for storm-water management strategy, suggestions are given to cope with inland flooding in different land scales in Wuhan. 


\subsection{Study Area Selection}

Local storm-water management problems are mostly solved individually rather than on the scale of water range. First, we outlined the watershed boundary on topographic and drainage map of the whole Wuhan district and divided the analysis watersheds into separate shape files. Then, we drew the links and the flow pattern of canals linking to sites and down-stream areas. This paper focuses on the watersheds located in Hongshan and jiangxia district in the northeast side of Wuhan (see figure 1). Measurement of independent variables was conducted using Geographic Information Systems (GIS) technology and aerial photography and watershed models were made for basic analysis. The Wuhan local government identifies 166 different watersheds in the City of Wuhan. This study will just include part of the lakes and water bodies. An important step is to identify the water boundary of lakesides such as Nanhu Lake, Shahu Lake in the land shape files and digitalized topographical maps with the right scale. The data are from various sources while the analytical data are based on the original geological sphere of Wuhan. In this study, the regional layer of Wuhan and Hubei province will be used for proper analysis graphically. Measurement chart of areas and regions will be created for analysis.

Table 1. The data source varies and the table below summarizes data sources used in this study

\begin{tabular}{|c|c|}
\hline Data & Source \\
\hline Main data for the analysis & Harvard University GIS Information Center (2010) \\
\hline comprehensive GIS global database & The Digital Chart of the World (DCW), \\
\hline special database of the world administrative areas & Global Administrative Areas (GADM) \\
\hline for use in GIS & \\
\hline The shape file of watershed for China & The shape file of watershed for China \\
\hline Road system and population shape file & Road system and population shape file \\
\hline Rivers of China & National fundamental GIS of China. \\
\hline The elevation data of Wuhan & CGIAR-CSI GeoPortal \\
\hline
\end{tabular}

Thanks go to all the organizations which provide the data for researchers to do the analysis, for their efforts in statistics collection contribute greatly to the progress of this field.

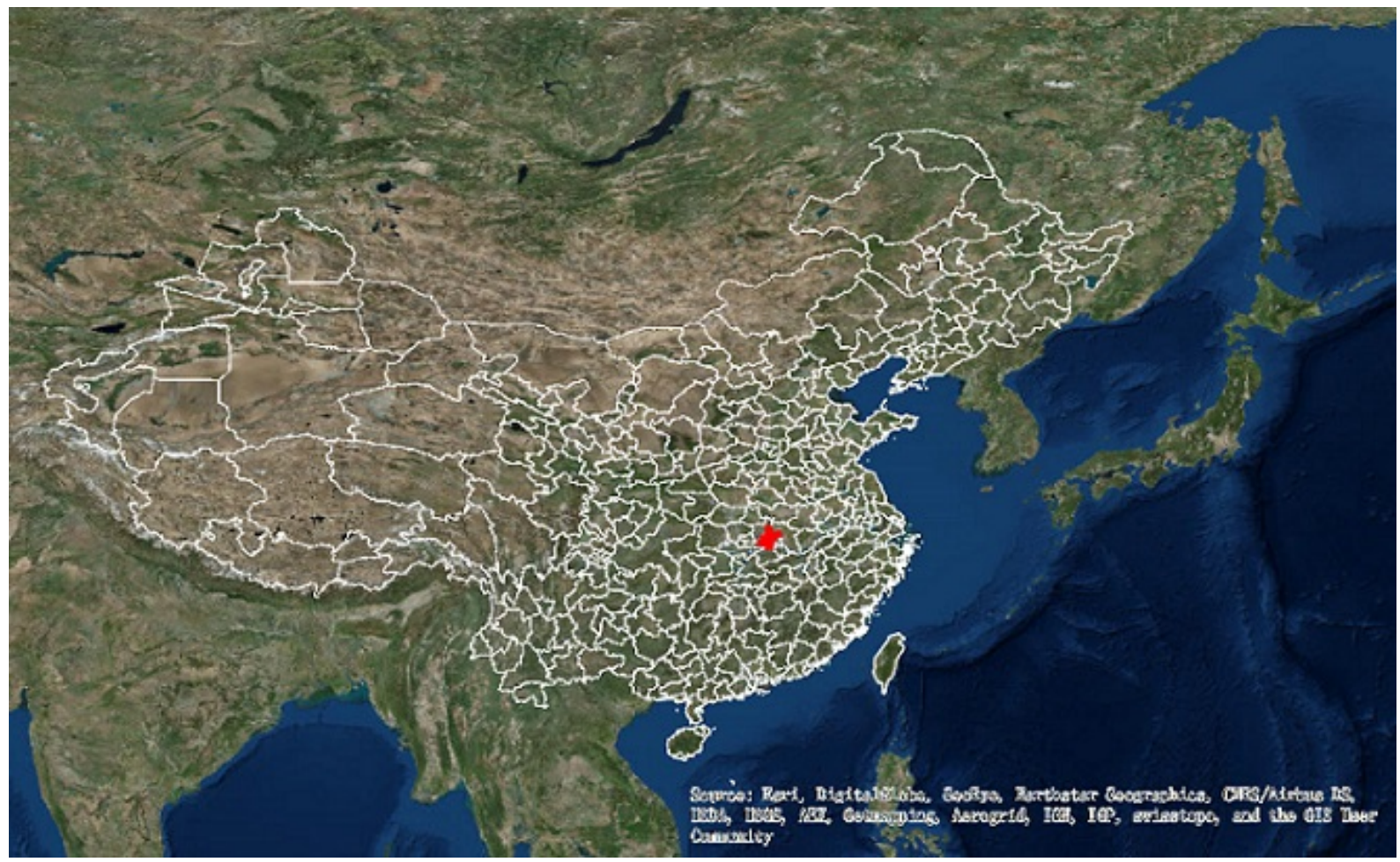

Figure 1. The location of Wuhan. (Data from Harvard University China GIS data base) 


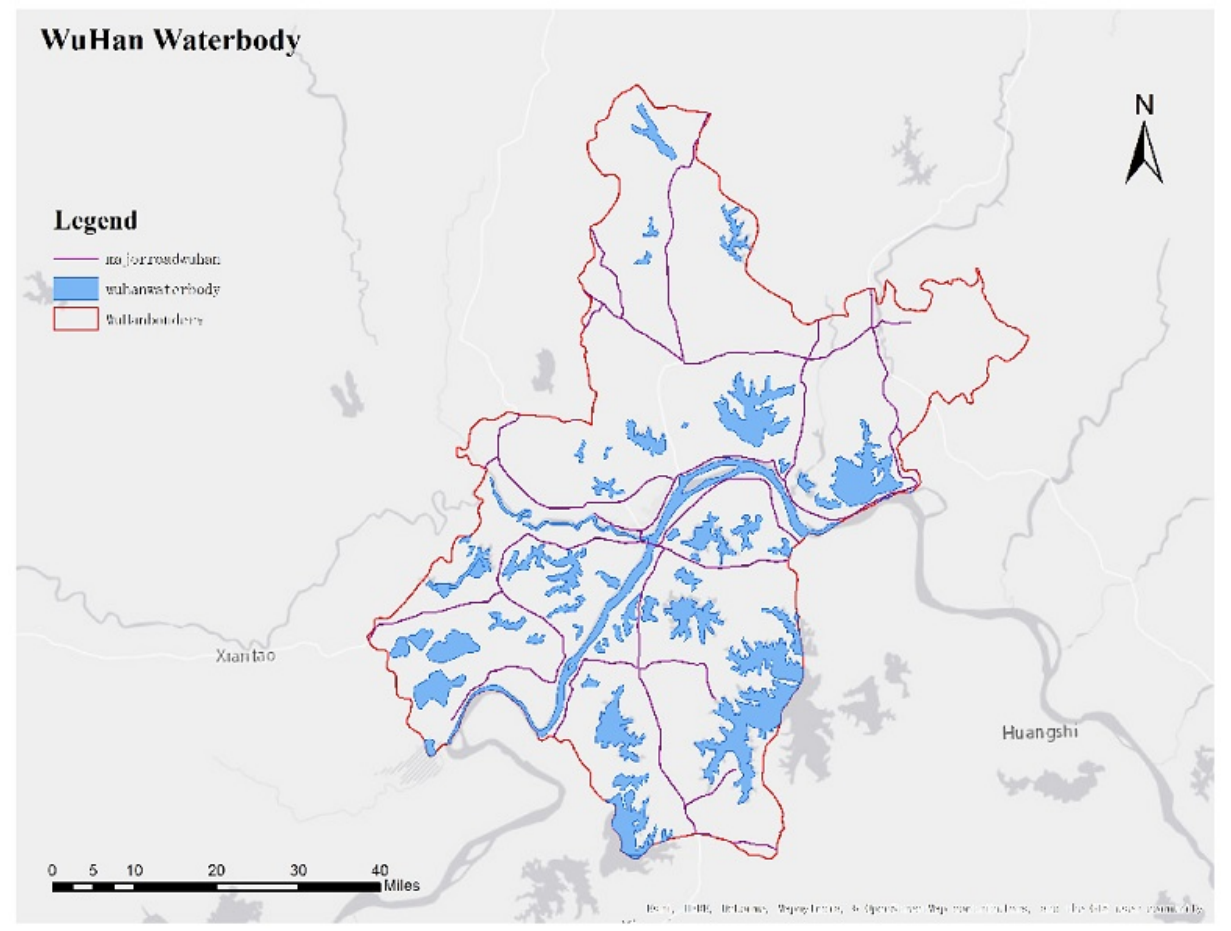

Figure 2. Main water body in Wuhan. (Data from Harvard University China GIS data base)

\section{Statistics and Data Analysis}

\subsection{Climate and Rainfall Frequency}

Precipitation of Wuhan is unevenly distributed over seasons every year and forms a regular pattern which can be clearly demonstrated with historical records. With a latitude of $30^{\circ}$ north, Wuhan is situated in the middle reaches of Yangtze River and under the influence of Jianghuai quasi stationary front, which works together with the large amount of steam produced by numerous lakes and rivers to produce rainstorms in rainy seasons. Wuhan's storms in the rainy season feature small area, strong intensity, short span and sudden attack, which meet all the conditions for the happening of inner city water logging and flooding.

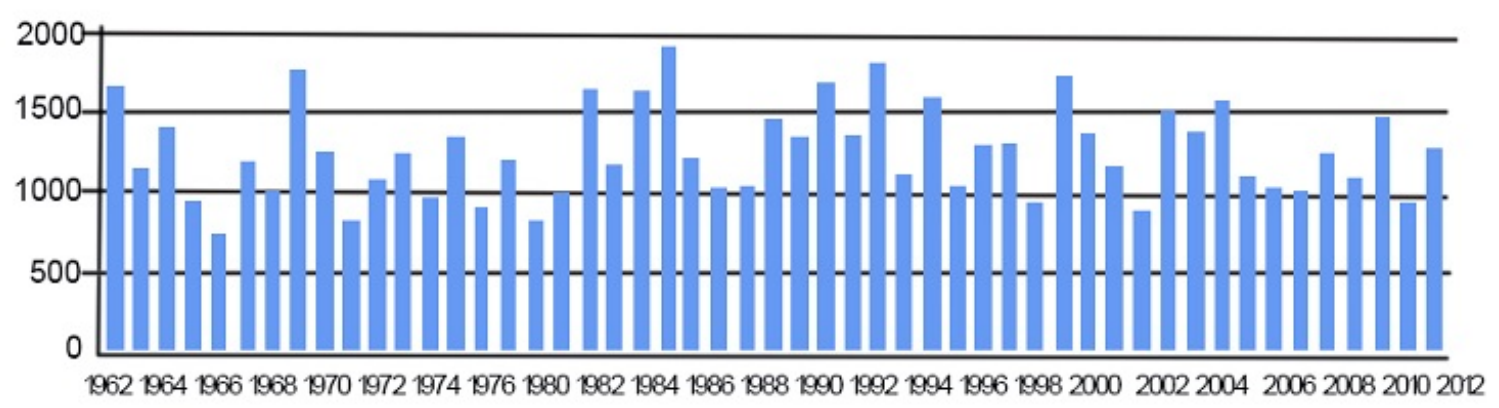

Figure 3. Precipitation of Wuhan from 1962-2012

Evidence shows that Wuhan's inner city water logging and flooding are closely related to the yearly precipitation pattern. In the past 50 years, Wuhan's highest daily precipitation vibrated among the years in a relatively fixed pattern. The change pattern is evident as the extreme figures of daily precipitation appear periodically. The years that experienced the extreme figures include 1969(261.7mm), 1982(298.5mm), 1991(209.8mm), 1998(285.7mm) and 2011(194.4mm) statistic from Official Journal of Wuhan water resource published by Wuhan Water Resource Management Bureau .Correspondingly, Wuhan was attacked by water logging and flooding in years of 1969, 1980, 1983, 1987, 1991, 1996, 1998, 1999, 2011, which may be the direct result of extreme daily 
precipitation. The total annual precipitation of Wuhan vibrated slightly in the last 50 years. From 1962 to 1979 , the annual rainfall decreased gradually and reached the bottom in 1979. After 1980 it rose steadily and climbed to the average number of the observed years in 1993, after which it vibrated slightly. From 1993 to 2004 it went up slowly and after that it reversed the trend and fell modestly from 2004 to 2012. In the observed years, only 1979 saw a dramatic change, which happened rarely in the history.

\subsection{Description of Watershed}

Shape Changing of Nanhu Lake in WuHan

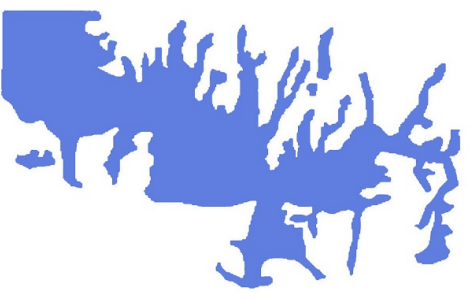

Nanhu 1989

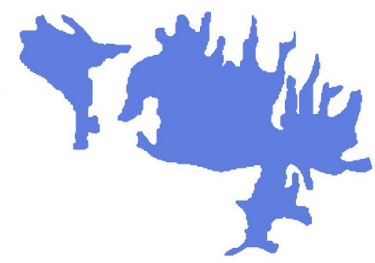

Nanhu 2000

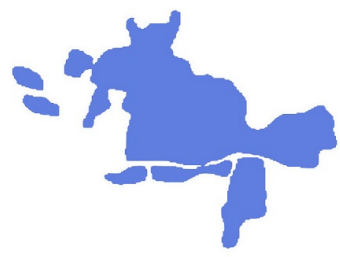

Nanhu 2009

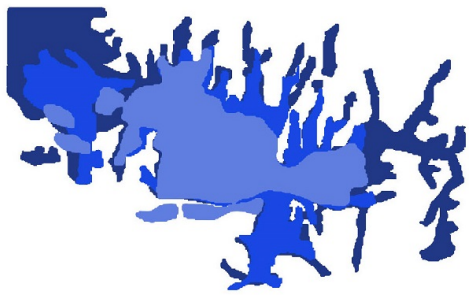

Overlay of Lake Shape

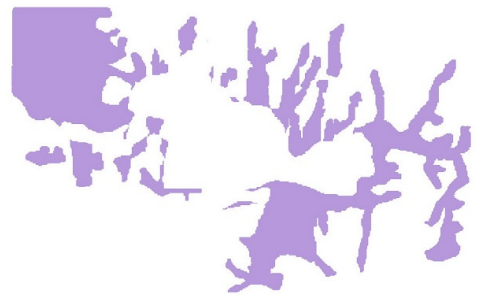

Reduced Shape

Figure 4. Shape change of Nanhu Lake in Wuhan

Wuhan boasts of large numbers of lakes, topping all the cities of China, which is unusual in the world. The lakes are surrounded by hills or drain large areas of plain. All the lakes are shallow, flat-bottomed and rich in aquatic lives, containing fresh water and demonstrating evident lake functions. However, with the quick pace of urbanization, the shape and area of lakes are changing, so their functions are consequently reduced, which can be demonstrated by the example of Nanhu Lake.

Nanhu Lake is located in the south of Wuchang linked to Shizi Hill in the south, farming villages in the north and east. As a central lake of Wuchang, Nanhu Lake has very favorable geographical environment and natural system. With an area of 49.2 square kilometers and an average depth of 2 meter, it is the second largest lake of Wuhan(Jing Wu 2010). With the expansion of the city, Nanhu Lake now has been included into the downtown area. As it links several universities, it has been transferred from agricultural area into a commercial and residential area. With the shift of its functions, its role in city management and development has been improved to a high level parallel to a core area of the city. However, this privilege has not brought to it special treatment in environmental protection. On the contrary, it has been most severely intervened by human development activities. Now this lake has been encircled by large number of high-rise buildings in three directions and its former boundaries have been altered by chemical factories and other engineering and lost its natural beauty. Agriculture, transportation and construction combined to cause the swift change and damage of Nanhu Lake. The change of Nanhu Lake from an area of clean water, fertile soil, rich natural resources to an over-exploited commercial and living center has brought great threats to its landscape beauty, recreational function and fascinating visual effects. In 1989 Nuhu lake has 1527.92 square hector meter, it has decreased to 1481.26 square hector meter(Jing Wu 2010) in 2000 and nine years latter in 2009 the lake shrank to 937.1 square hector meter. With the quick steps of lake filling and land use change, 590.82 square hector meter lake area disappeared and changed to buildings and hardened surface.

Shahu Lake is located in the north-east of Wuchang, connected with Zhongbei Road in the east, Little Turtle Hill in the south, Wuchang-Daye Railway in the south and Xudong Road in the north. A hundred years ago, Shahu 
Lake was connected with East Lake in the east and Yangtze River in the west, however, the three were separated after the construction of the Wuchang-Qingshan embankment. At the end of Qing Dynasty Beijing-Guangzhou Railway was built to go through Shahu Lake and divide it into two parts: Inner Shahu Lake and Outer Shahu Lake. The Inner Shahu Lake was smaller and was eaten up by expanding of the land area while the Outer Shahu Lake, the bigger one remains still to the east of the railway and is the only lake in the downtown area of Wuhan. The inner Shahu lake shrank from 28.25 square hector meter in 1989 to only 6.05 square hector meter in 2009 . The outer Shahu lake faced even more serious lake fill, from 1989 to 2009265.8 square hector meter lake area were occupied for other use (Jing Wu 2010).

\subsection{Land Use}

In Wuhan, lakes are filled up and turned into agriculture land, construction land or traffic land. For example, between 1989 and 2000, the transformation of lakes into arable land mainly happened in Wuchang and Hanyang. Shahu Lake of Wuchang was the most severely attacked, for it has a water region with the total area of $16.62 \mathrm{~h}$ $\mathrm{m}^{2}$ south of Xudong Road and north of Outer Shahu Lake bordering the railway transformed into cultivated field. At the same time, large areas of lakes are filled and become construction land. From 1989 to 2000, Hanyang's major lakes like Moon Lake, Lotus Lake, Longyang Lake and Taizi Lake were all partly filled to create place for construction, among which Taizi Lake is filled by the largest area. A total of $27.54 \mathrm{~h} \mathrm{~m}^{2}$ converted into construction land. Another use of lake areas is for the expansion of traffic system. From 1989 to 2000, the Houyang Lake of Hankou was occupied by the newly-widened Qingnian Road by an area of $0.58 \mathrm{~h} \mathrm{~m}^{2}$ and two new roads crossing Zhangbi Lake covers an area of $1.22 \mathrm{~h} \mathrm{~m}^{2}$ (Jing Wu 2010) of that lake. A natural result of lake decrease is the rise of lake water level and the lowering of their storing capacity. Still another effect is the damage of the natural beauty of lake banks formed in history by the newly-built hard-material artificial banks.

\section{Discussion and Suggestion}

\subsection{Stormwater Management in Neighborhood Scale}

Wuhan's top 20 serious flooding points (about $40 \%$ of the total) are located in residential areas which require urgent attention (WWRMB 2010). Controlling this situation can start with the basic strategy of sustainable design that is collecting, storing and reusing of rain water. Rainwater collection can help to solve the problem of flooding and city water logging, whether it is roof rainwater or ground rainwater. As for roof rainwater, a simple way is to make use of roof water line and water filtering pipes to lead the clean water to a roof tank. Water collected in this way can easily satisfy the demand for toilet flushing, road cleaning and plants watering. Underground tanks can be connected to city water supply system to be an additional source of water, to satisfy the need for industrial production, citizen life and ecological use of water.

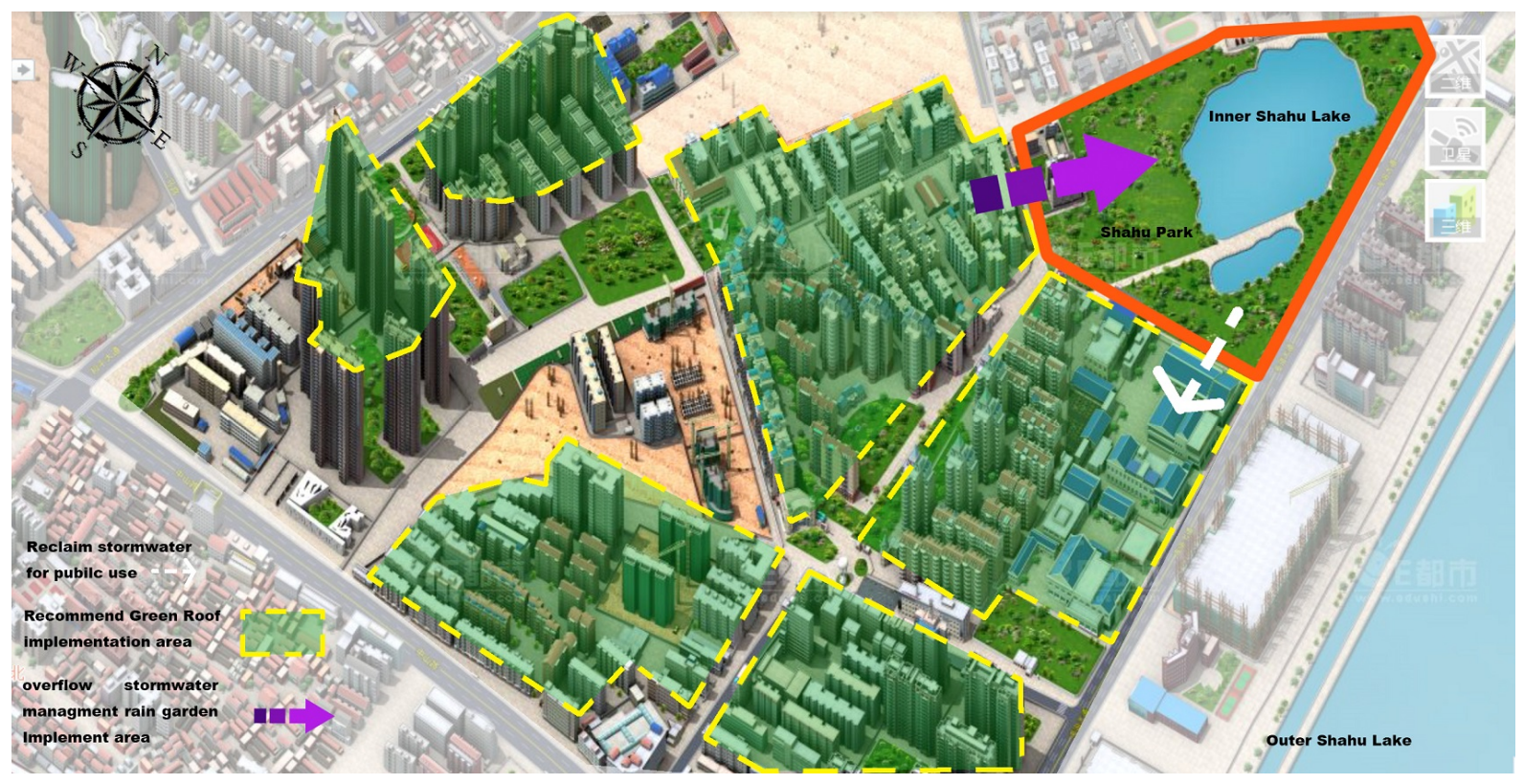

Figure 5. Suggested area for implementing stormwater management (Base Map from Wuhan E City)

Figure 5 shows the existing inner Shahu lake and the newly developed residential area, which is a great place for 
the implication of residence area improvement in cooperation with city public parks. From previous analysis, inner Shahu Lake shrank because of land use change and city development. One effective way to conserve both wetland in the inner Shahu park and manage water is to build stormwater management facility in the nearby residential area. Those Green infrastructure will collect overflowed storm water to rainwater pipes then the water will go directly to the rain garden in the wetland located in Shahu lake Public park, after days of reclamation and filtration purified storm water could go back to the water container in the nearby residential area and be used as toilets flush water or road wash water. Till then the water could cycle by itself rather than be evacuated by pumping facilities in raining season. The green range with yellow dash is marked as green roof improvement area. In the residence area rain fall goes directly on the Green Roof, then green roof will keep part of it and the over-flow will go to rain pipes first, and then to filtration pool or the detention cistern under building. Filtration pool will link with small range rain garden in the society. Public park wetland will link with rain garden the over-flow of rain garden will then go to city sewer. In this way, the infiltration area will be expanded and wet land near lake will get enough supply of water by link with rain garden,

As for the space aspect, changes can be made in three parts: upper space, ground surface and underground facilities. As for upper space like architecture and inner building space, green roof and storm water pipe would be the basic improvement while for the ground space, biofiltration system and small range storm water garden can work to help solve the problem. As far as the underground space is concerned, facilities such as reservoir and water alley will make a big difference.

Creating the green roof collecting facilities may immediately increase the collection area and improve the situation. Commonly used strategies include creating vegetated roofs. Light weight plants and high tolerant plants for drought and temperature variation should be considered. The green roof can capture most of the rainfalls, though the amount of rainfall that can be caught depends on the density of greenery and the amount of rain fall. Also, green roof not only can capture some of the rainfall but also can detain the run off for later release That's a very important point because it can release the pressure of the water drainage for the picked time, thus minimizing the community flooding possibility.

Biofiltration System is a vital part of residential area storm water management. It is a one of the best choices for city facing similar situation like Wuhan. As part of Low impact development, this strategy takes the most consideration of the environment and it includes steerages like bio retention, green roof , primary filtration treatment such as pervious pavements. Residential biorentention green alley and biorentention basins are usually built between buildings to reduce the run off volume and link the rainwater garden. In newly developed residential areas water management strategies of catching water from roof top and leading water to water storing facilities which are scattered in the residential area are adopted. In this process the falling water can be primarily cleaned. Then, the water goes to infiltration area that can offer larger area for infiltration or bioretention green alley. For residential roadside storm water management, the situation is different. Rainfall may need three kinds of road surfaces: impervious surface, green field and pervious pavement, among which the best choice is green field because the vegetation layer will absorb most of the falling water to supplement underground water. The effective arrangement for impervious road is to create road side infiltration alley which can lead storm water to rain gardens and bioretention basins. Infiltration plants can provide good drainage area for both parking lots and sidewalks.

Many studies have proved that the previous pavements could decrease surface storm water runoff. Different design choices can be made according to the site situation when choosing pervious pavement. There are four main alternatives for the design for previous pavement: concrete grid pavers, porous concentrate and asphalt, reinforced grass pavement and gravel paving. Porous asphalt as an important strategy for residential area roads has many advantages. The most obvious advantage of porous asphalt is that it is built above the uncompacted subgrade. Clean crush stone in single-size are often placed on top layer. Asphalt allowing water to infiltrate down to underground and find it's way to streams, ponds and lakes. The space between sidewalk and street could be vegetation drain alley which create a buffer zone between sidewalk and vehicle road, turf blocks could create private and workable pavement for pedestrians.

Swales are also considered the irresistible part of infiltration area. Area between parking lots can be great choice for the swales. Vegetated swales are now wildly applied as useful design strategy not only because it has various functions for storm water management but also it can be made as one of the best places for underground reservoir (EPA 1999). Alternative slope could be made for the surface run off. From parking lots to swales, water could be primarily cleaned by the vegetation side in the swales. Overflow drain linked with underground reservoir could enlarge the endurance to face the heavy rainfall. Underground reservoir as a supplement to swales also could be used for roof water collection and reuse. 
In the storage cession, underground water reservoir and other water storage facility helps to stagger the peak point of water drainage. Moreover, rainwater that has been primarily cleaned could be reused as green roof irrigation water and domestic water usage for daily cleaning and road wash. This whole water cycle could save more water and decrease the inundation directly.

Ground rainwater can play a great role since Wuhan hosts large squares and developed road systems. Wuhan's public squares and roads are mostly asphalt concrete pavement. Ground rainwater can be collected through conducting canals linked to storage facilities. Rainwater on collecting planes near water body can be gathered through natural landscape. As Wuhan has varied land forms and the scientific design of a collecting system can efficiently conduct the flowing of water to the nearby water bodies such as lakes and rivers. Additionally, lowered green belt or plant-covered conducting ditches can be constructed to let rainwater flow through green belt and increase the filtering of rainwater to add to the underground water supply. The filtering of green belt can be helpful in the purifying of rainwater.

\subsection{Stormwater Management in Watershed Scale}

Wetland ecosystem as part of the nature assumes an irreplaceable part offering free services to both local people and wild lives. What's more important, lakeside wetland is considered to be one of the very effective storm water management area. Wuhan as a city of lakes contains wide range of lakes and wetlands which adjust storm water and microclimate in one way or another. With the development of the city, the land changes from time to time and this influences many aspects of both human and wildlife. During the city construction and development, wetland protection and public park development has been ignored, which leads to sever habitat fragmentation and wetland decrease. To protect the existing wetland and rebuild the sensitive area near lakeside could be great ways to manage storm water. To improve and rebuild the natural cycle which has been destroyed new protection wildlife corridor has to be constructed. To prevent habitat fragmentation, storm water improvement strategy should be employed. One of them is to make use of local parks and increase conservation area. According to the existing park map in Wuhan, local parks are scattered in the city and most of the public parks are close to lakes. They offer a great opportunity for storm water management and wild life reconstruction. Problems of Wuhan 's public parks are as follows. First of all, water pollution of lakes is still severe. Secondly, the links between parks and lakes are weak. Thirdly, city parks do not have clear functions of storm water management and ecosystem protection. Some of the parks are isolated in the city. Others are over constructed. For instance, most of the lakeside parks are with hard concrete revetment and others may have enough lakeside green fields but surrounded by construction land and polluted by untreated storm water that need to be clean and maintained. To solve those problems, actions are required in different aspects.

Lakeside life belt will be constructed, because this life corridor between the lake and the agriculture fields will preserve the habitat of life species in the lake areas and protect the migratory channel of animals living in the lakes. Additionally, this buffer area can also absorb the nutrient rich pollutants from crop fields, retain earth and reduce soil erosion and protect birds and other wild lives. In order to fulfill the expected functions, the following points will have to be followed. First, the buffer belt should be as complete as possible to ensure the totality of the corridor and reduce human interference. Second, life diversity in the lake has to be stressed to ensure the health operation of natural ecology and healthy interaction between all species in the same environment. Third, local plants will be chosen for the corridor to avoid the introduction of alien species or domestication of wild creatures.

In the process of life belt building, the following steps will be essential: First, right decision should be made on the width of the green corridor. In the light of the functions of retaining fertility of crop fields bordering on the lake and the nourishing of the habitats of life species in the lake, a width of $10 \mathrm{~m}$ is usually recommended by experts as it is appropriate and beneficial to the ecological system. Second, efforts should be made to protect the living reeds and calamus and give them the least interference and give their environment preserving capacity a full play. Third, the local animal species should be protected so that their movements will not be disturbed. For those animals not so mobile, efforts will be made to restore their favorite surrounding to best enhance their growth and reproduction. Forth, it is important to time human handling of creatures in the corridor carefully so that the interference and negative effects on their life will be reduced to the least.

In the aspect of park improvement, wet land creation and storm water management much work needs to be done too. Wetland is greatest place for ecosystem recovery and biodiversity protective area. Wuhan, a city with so many lakes and parks don't have even one wetland conservation park. When people talk about park the first thing coming into their mind is the recreation function of the park. Park designers give the recreation facility and tourist development the first priority but ignore ecosystem management and water conservation, which leads to 
over construction and too much human interference. The development of Wuhan's conservation park does not have long history. Storm water management function has not been stressed till recent years of park design. City parks have been divided into two types: urban parks and suburb ones. Urban parks include comprehensive parks, specialized parks and community parks. Suburb parks include scenic spots, natural protection areas and agriculture parks. Suburb parks are far away from city area and not easily reachable. Urban parks are mostly created for recreation and cultural functions.

To change the situation, more scientific strategies need to be adopted. First of all, links should be created between the green patches in urban areas. Storm water management functions of lakeside parks should be enhanced, large infiltration area for nearby community should be created. Small range community rain gardens should have certain green corridor in between both underground and spatially. Wetland should be recovered in lakeside parks and human interference for these wetlands should be reduced to the least. From ecological perspective the better way of conserving wetland is to create better connective corridors with parks so that wildlife can have larger areas to move around. In storm water management perspective, it is better to move preliminary water into larger areas to be purified and reused. Part of the wetland ecosystem services is water reservation and drainage. Secondly, it is a good idea to use greenery and have metal absorption plants for storm water treatment and remove bacteria. Untreated rain water could be retreated in the newly constructed wetland areas. Many experiments have been done to treat road run off. Bioretention is one way to remove heavy metals from infiltration storm water. One of the field studies suggests that the bioretention is effective with removal of zinc, lead and copper. As a part of the American Low Impact Development green belt near parking lots could help for the removal and management of run-off water. Wuhan's lakeside parks have similar vegetation layers, so improving the greenery type is one of the improvement worth trying. According to the statistics of ecological adaptation plants in the wetlands of Wuhan about 137 different types of the wetland plants are local that includes Hygrophytes 91, Halophytes 11 and Hydrophytes 35 (Song guangying 2008). Protecting these various types of plants is part of the duty of these wetlands. Some of the plant like Typha angustifolia, Phragmites australis and Nelumbo nucifera are great choice both for wetland water retreatment and value of view.

Thirdly, it is important to reform certain stream's waterways and reduce the flow velocity by filter stone. Heavy storm would create large amount surface run off, so it helps tremendously to drain away falling water by vegetation ally that can lead water to rainwater garden. From overflow drainage gutter to large drainage area the water could be cleaned the second time by filter stone which size differently from upper stream to lower stream. In large lakeside, conservation park longer storm water management ally could be created in the wetland side. Successful examples have been created in different parts of the world. In addition, to reduce the human interference of wetland defense and protection contracts should be signed and identified. Another effective practice is to reduce the hard lake bank to natural riverside and rebuild life cycle of the lakeside both in animal perspective and plant perspective. Additionally, illegal fishing must be banned and local plants should be protected.

\section{Conclusion}

Based on the analysis above, it is evident that Wuhan inland inundation and storm water management problems are related to many factors and require immediate efforts to address and tackle. Considering both the city development and nature conservation in early stages of planning and design is crucial for the future of Wuhan. To protect what the city has and manage to recover what has been lost is the best strategy. However, it is not enough to find out inundation points and deal only with the small isolated parts. Considering the problem as a whole in long-term perspective with the aim to recycle water in the whole city is the recommended direction. Water inundation problem is a common problem accompanying the development of the city. To deal with the issue, it is critical to start improving the management infrastructure facilities and use bioretention strategies to create more sustainable drainage systems.

First of all, in the urban planning scope, the improvement of pumping system is indispensable, the maintenance and reconstruction of imperfect sewer system also can't be ignored and to raise storm resistance capacity of sewer system could let the city be prepared for heavier rain storms. Secondly, Lake filling must be strictly restrained as the problem created by wetland damages and lakeside water pollution could have severe consequences. Thirdly, implementing of water recycling and rain garden construction should be stressed. In neighborhood scale, the application of green roof, detention cistern and other supplementary facilities are needed. These improvements could raise the level of water use efficiency directly. Residential areas are basic unity in city and their large range development could make great difference. In addition, large range natural water reclaiming area and inner city smaller range rain garden could be constructed. In that way, more infiltration areas are created for the city as supplement of underground water. We can't change the general geographic form of the 
land but we can control water run off direction purposely by giving little slop between two sides of the road or building bioretention ally.

Watershed as an important part of Wuhan's city development is the link between wildlife, people and nature environment. The watershed changing history reflects not only the development of the city, but also how human activities conflict with nature, during which process we see the conflict and compromises between nature and people. Through the process of conflicts and compromises between nature and people, one can see also how people and nature are linked together to coexist. This study analyzes the changing conditions of the three main lakes in Wuhan. Based on the analysis results, it is recommended to use GIS information system statistics to find the optimum way to manage and protect the lakeside life cycle and manage storm water sustainably to mitigate the risk of city inundation and inland flooding problems.

\section{Acknowledgments}

I would also like to extend my sincere thanks to my advisors at the College of Design, Construction and Planning (DCP), University of Florida for their guidance and support.

\section{References}

Butler, D., \& Davies, J. W. (2000). Urban Drainage. London. 11 New Fetter Lane. E \& FN Spon EPA Storm Water Technology Fact Sheet Vegetated Swales September 1999. Retrieved from http://water.epa.gov/scitech/wastetech/upload/2002_06_28_mtb_vegswale.pdf

Chahar, B. R., Graillot, D., \& Gaur, S. (2012). Storm-Water Management through Infiltration Trenches. Journal of Irrigation and Drainage Engineering , 138(3), 274-281. http://dx.doi.org/10.1061/(ASCE)IR.1943-4774.0000408

Chen, W. D. (2014). Analysis to the potential and feasibility of rainwater resources utilization in urban area of Wuhan publisher. Central China Normal University. Wuhan, China.

Digital Chart of the World -- Roads -- Rivers-- Railroads

Elliott, S. A. T. (2007). Environmental Modeling and Software. ENVSOFT, 22(3), 394-405.

GIS Data

http://www.fas.harvard.edu/ chgis/

http://www.fas.harvard.edu/ chgis/data/chgis/downloads/v4/

http://www.fas.harvard.edu/ chgis/data/dcw/china/

http://www.fas.harvard.edu/ chgis/index.html

Jing, W. (2010). An Empirical study of Wuhan lakefront landscape changes. Publisher Huazhong university of science and technology.

Marsalek, J., \& Schreier, H. (2010). Innovation in Stormwater Management in Canada: The Way Forward. water quality research Journal of Canada.

Martina, C., Ruperd, Y., \& Legreta, M. (2006). Urban stormwater drainage management: The development of a multicriteria decision aid approach for best management practices.

Song, G. Y. (2008). Studies on plant diversity of urban lake wetland in Wuhan. Huazhong Agriculture University. Wuhan, China.

Wang, F. Z. (2010). Evaluation on the ecosystem services values of urban lake wetlands a case study of urban lake in Wuhan city.

Wuhan Water Resource Management Bureau Official Journal of Wuhan water resource. Retrieved from http://www.whwater.gov.cn/water/

Zhou, G. Q. (2013). China Daily. Retrieved from http://www.chinadaily.com.cn/dfpd/dffcjj/2013-07-08/content_9522601.html

Zhu, S. C., \& Ren, X. Y. (2011). Thought about China inland inundation problem. Retrieved from http://theory.people.com.cn/GB/16281866.html

\section{Copyrights}

Copyright for this article is retained by the author(s), with first publication rights granted to the journal.

This is an open-access article distributed under the terms and conditions of the Creative Commons Attribution license (http://creativecommons.org/licenses/by/3.0/). 